\title{
A dêixis pessoal na aquisição de linguagem: uma perspectiva enunciativa
}

\author{
José Temístocles Ferreira Júnior* \\ Natanael Duarte de Azevedo**
}

\begin{abstract}
Resumo
Neste artigo, buscaremos discutir o processo de enunciação a partir da relação mãe-bebê, observando o uso dos dêiticos pessoais pela mãe e sua emergência na fala do bebê enquanto marca do processo de subjetivação. Para isso, utilizaremos as considerações de Benveniste a respeito do processo enunciativo, no que diz respeito ao funcionamento dos pronomes pessoais $e u$-tu. Analisamos, de forma interpretativa, dados longitudinais de uma díade mãe-bebê ao longo de 36 meses de vida da criança, em situação naturalística de interação. Os resultados mostram que, ao analisar o uso dos dêiticos pessoais na relação dialógica, é possível compreender a marcação dos papéis discursivos assumidos na interação como constitutivos da própria subjetividade e também o processo de enunciação por parte do infans.

Palavras-chave: Dêixis pessoal. Enunciação. Constituição do sujeito.
\end{abstract}

\section{The Personal Deixis in Language Acquisition: an Enunciative Approach}

\begin{abstract}
In this article, we will try to argue the process of enunciation from the relation motherbaby, observing the use of the personal pronouns (personal deixis) used by the mother and her remarks on the baby's speaking as a remark of the subjectivity process. Thus, we will rely on Benveniste's reflections regarding the enunciative process, to what refers the functioning of the personal pronouns I-you. We have analyzed, in an interpretative way, longitudinal data in a relation mother-baby for 36 months of the baby's life. The results show that, analyzing the personal deitics in this dialogical relation, it is possible to understand the corresponding discursive roles taken in this interaction as constitutives of its own subjectivity as well as the enunciative process performed by the child.
\end{abstract}

Keywords: Personal deixis. Enunciation. Subject constitution.

Recebido:16/01/2018

Aceito:04/05/2018

\footnotetext{
1 Universidade Federal Rural de Pernambuco (UFRPE). Mestre e Doutor em Linguística, com ênfase em Aquisição da Linguagem e Linguística da Enunciação. Professor adjunto II da UFRPE.

2 Universidade Federal Rural de Pernambuco (UFRPE). Professor Adjunto. Atua nos cursos de graduação das Engenharias na Unidade Acadêmica do Cabo de Santo Agostinho (UACSA/UFRPE) e no Programa de Pós-Graduação em História da UFRPE.
} 


\section{Considerações Iniciais}

A discussão acerca da relação entre subjetividade e linguagem não constitui um ponto novo no campo de estudos da Linguística. Mesmo antes da publicação do Curso de Linguística Geral, de Ferdinand de Saussure, no gesto que marcou a fundação da Linguística moderna, estudiosos como Humboldt (1874) e Bréal (1924/1897) já haviam se preocupado com a importância da inserção do sujeito nos estudos da linguagem. No entanto, para adquirir o estatuto de ciência, a Linguística teve de operar, a partir da publicação póstuma da obra de Saussure, uma série de exclusões, colocando na exterioridade de seu objeto de investigação - a língua - questões como a subjetividade, a enunciação, a referência (TEIXEIRA, 2000), o que caracterizou o chamado imanentismo linguístico, ou seja, o estudo da língua se encerrava nela mesma. Desse modo, destacamos com Flores e Teixeira (2005, p. 29), que Benveniste figura como um dos primeiros autores, a partir do quadro saussuriano, a desenvolver um modelo de análise da língua especificamente voltado para enunciação, trazendo em seu escopo o elemento subjetivo como ponto indispensável para se estudar a língua.

Desde então, a relação entre o sujeito e a linguagem tem sido colocada sob diferentes enfoques e perspectivas nas diversas linhas que integram a Linguística, sobretudo a partir da segunda metade do século XX, e o modo como o sujeito é tomado, nessas correntes linguísticas, é decisivo para definição mesma do ponto de vista em que será abordado o objeto de investigação - a língua(gem). Mas, se é verdade que as perspectivas que transcendem o imanentismo linguístico se valem necessariamente de algum sujeito, como afirma Teixeira (2000), o modo de concebê-lo não constitui, por outro lado, um ponto pacífico.

Neste trabalho, objetivamos discutir alguns postulados de Benveniste (1988 e 1989) acerca do sujeito na linguagem e quais as implicações destes postulados na aquisição de linguagem. Para isso, partiremos da observação do uso da dêixis pessoal na relação mãe-bebê, sob o pressuposto de que a língua é o lugar de expressão e de constituição de subjetividade (em que a relação dialógica eu / outro é explicitada) e de que a dêixis constitui o primeiro ponto de revelação do sujeito na língua, para tentar mostrar de que modo a dialogicidade presente nas interações mãe-bebê se evidencia no processo de enunciação e qual o estatuto da aquisição da linguagem na constituição do sujeito. Iremos nos valer de dados longitudinais de duas díades mãe-bebê (ao longo dos 36 meses de idade do bebê), em situação naturalística de interação ${ }^{3}$, tendo como suporte teórico os estudos desenvolvidos por Benveniste (1988 e 1989) e Flores et al. (2008), entre outros. Os resultados mostram que, através da observação das produções enunciativas do infans, é possível vislumbrar as mudanças da relação do sujeito com a língua, com o outro e com sua própria subjetividade, na aquisição de linguagem.

\section{Sobre a dêixis na aquisição da linguagem}

A preocupação com o modo de referir da linguagem tem impulsionado, desde muito tempo, uma gama de pesquisas de variadas naturezas teóricas e com propósitos igualmente diversos no campo da Linguística. Desse modo, os estudos linguísticos se voltaram para um grupo de partículas presentes na língua cuja função seria essencialmente a de indicar elementos como temporalidade, espacialidade e pessoalidade e o abrigaram sob o rótulo de "dêixis", muito utilizado até hoje no campo da Linguística, mormente em estudos sobre referência / referenciação na linguagem.

Comoé sabido, esses três elementos, de alguma forma, sempre estão envolvidos em outros fenômenos

3 O termo "interação" é tomado aqui, sob um senso lato, como um conjunto de trocas interpessoais por meio das quais os sujeitos constituem mutuamente as diversas formas e possibilidades de sentido. Desse modo, podemos pensar a enunciação como uma das possibilidades de efetuar a interação. 
linguísticos e, talvez por essa razão, as pesquisas sobre a dêixis aumentaram consideravelmente nos últimos 50 anos, sendo criadas, inclusive, algumas tipologias de dêixis nos mais variados estratos linguísticos, como mostraremos mais à frente. Porém a natureza (subjetiva) de cada elemento da tríade temporalidade-espacialidade-pessoalidade que sustenta o fenômeno dêitico nem sempre foi esclarecida, bem como sua correlação no sistema da língua.

Neste artigo, pretendemos nos deter sobre a categoria de pessoalidade na dêixis sob o escopo de indicar sua natureza, seu funcionamento e sua função na aquisição da linguagem. Nossa investigação aqui se debruça sobre a relação entre a aquisição dos dêiticos ditos pessoais e o processo de constituição do sujeito, porém, antes expor de nossa visão sobre o assunto, compete-nos primeiro situar a temática da dêixis (sobretudo, a dêixis pessoal) nos estudos linguísticos, desde suas principais perspectivas, até seus maiores impasses, para depois destacar a necessidade de se abordar a dêixis na aquisição da linguagem sob uma perspectiva enunciativa.

De uma maneira geral, a hipótese que permeia nossa pesquisa é a de que a aquisição da dêixis pessoal está intrinsecamente atrelada ao processo de constituição subjetiva, pois à medida que o sujeito busca para si um espaço na enunciação torna explícita a natureza subjetiva e intersubjetiva da linguagem. O termo "dêixis" remonta aos gregos e abrangia todos os elementos linguísticos que servissem para apontar coisas no mundo, como que "com o dedo". Desse modo, a dêixis possuía um caráter notadamente ontológico. Com o tempo, essa noção sofreu elasticidades e passou a designar elementos linguísticos que indicassem ou representassem noções de temporalidade, lugar, objetos e pessoas ${ }^{4}$ (LYONS, 1977). Salvo algumas exceções, a maioria dos investigadores da dêixis parte dessa acepção.

Porém, no decorrer dos estudos linguísticos, essa abordagem, talvez por conter um caráter muito abrangente, sofreu várias alterações, levando, inclusive, alguns pesquisadores a adotarem outros termos para se referir aos "dêiticos". Lahud (1979) elenca alguns: "símbolos ou signos indicadores", “símbolos-índices" ou mesmo "indicadores", todos usados por Peirce (1975); "shifters" 5, expressão introduzida no inglês pela primeira vez por Jespersen (1923) e bastante usada por Jakobson (1984); "indicadores de subjetividade", "índices (ou signos) do discurso", "índices (ou signos) da enunciação", termos preferidos por Benveniste (1988). Naturalmente, a utilização de diferentes termos para se referir ao mesmo fenômeno revela as diferentes posições teóricas sobre a questão. Nessa pesquisa, decidimos utilizar o termo "dêixis" (mesmo sabendo da problemática que gira em torno dele) pelo mesmo motivo apresentado por Lahud (1979): essa é, muito provavelmente, a designação mais conhecida e difundida no campo da Linguística.

Outros autores (HANKS, 2008; LEVINSON, 2007; APOTHÉLOZ, 2003; entre outros), entretanto, optaram por criar subclasses dentro da noção convencional de dêixis, subdividindo-a, por exemplo, em categorias ${ }^{6}$ como: "dêixis verbal" que diz respeito aos verbos que comportam morfemas indicadores, sobretudo, de noções de tempo / pessoa (ver, por exemplo, LEVINSON, 2007); "dêixis adverbial ou espacial" que abarca termos da língua que servem para localizar eventos, atividades e objetos no espaço (ver LYONS, 1977); "dêixis textual ou discursiva" que abrange termos ou expressões usadas para se referir a uma porção ou aspecto do discurso (verificar LYONS, 1977; MARCUSCHI, 1997) e "dêixis pronominal ou pessoal" que diz respeito a todos os elementos linguísticos que, de alguma forma, designam a pessoa no discurso ${ }^{7}$.

4 Acreditamos que essa perspectiva seria suficiente para afirmar que os nomes também fazem parte da dêixis ou mesmo podem assumir uma função dêitica.

5 No francês, a palavra recebeu a tradução como "embrayeurs"; no espanhol (versão a que tivemos acesso), o termo utilizado é "conmutadores". No português, há várias traduções como "embreantes" e "embreadores" (ver FLORES e TEIXEIRA, 2005; LAHUD, 1979). Optamos por utilizar o termo "shifters" por ser bastante difundido no campo da Linguística.

6 Há outras classificações.

7 Levinson (2007) trata da questão da dêixis pessoal no contexto dos outros dêiticos. 
O pano de fundo dessa discussão parece, por um lado, ser o critério adotado para definição e para classificação da dêixis e, por outro, a compreensão da relação não coincidente entre formas e sentido na linguagem. Na conhecida Gramática de Port-Royal, Arnaud e Lancelot (1660/1992) tratam a questão da dêixis sob um viés quase que puramente estilístico, afirmando que, "Como os homens foram obrigados a falar muitas vezes das mesmas coisas num mesmo discurso e fosse monótono repetir sempre as mesmas palavras, inventaram certos vocábulos para substituir esses nomes, sendo por isso denominados pronomes." (ARNAUD; LANCELOT, 1660/1992, p. 57).

Nessa afirmação, podemos verificar tanto uma concepção de que linguagem é uma nomenclatura, quanto a ideia de que os pronomes teriam a função unicamente de evitar a repetição enfadonha dos nomes a que se referem. Os autores prosseguem, ainda, fazendo a distinção entre os pronomes de primeira pessoa (que substituem aquele que fala), os de segunda pessoa (colocados no lugar daquele a quem se fala alguma coisa) e os pronomes de terceira pessoa (que representam coisas ou pessoas de quem se fala). Como bem destacou Lahud (1979, p. 51) a respeito dessa separação, "nenhuma oposição estrutural no interior das três pessoas pode ser assinalada quando se salienta o papel substitutivo dos pronomes em relação aos nomes (...)”. Conforme o autor, quando se trata das relações discursivas entre as pessoas, é necessário operar uma distinção entre as duas primeiras pessoas e uma não pessoa e tomá-las por uma ótica relacional.

Lahud (1979) aponta ainda que há, nessa separação dos pronomes feita por Arnaud e Lancelot (1660/1992), uma oscilação de critérios para distinguir as duas primeiras pessoas e a terceira: quando tratam dos pronomes, os autores recorrem a um critério nocional, afirmando que os pronomes apenas substituem os nomes, mas ao mesmo tempo, no capítulo destinado ao estudo dos verbos, os autores afirmam que a terceira pessoa pode representar coisas e, por isso, é definida opositivamente em relação às duas primeiras pessoas, pois diferentemente do par eu / tu, a terceira pessoa é caracterizada pela ausência de relações pessoais. Ora, isso deixa claro que Arnaud e Lancelot (1660/1992) adotaram também um critério estrutural ou oposicional para tratar dos pronomes, fato que tornou imprecisas ou insuficientes suas explicações acerca da real natureza da categoria de pessoa do discurso à qual se atrelam os pronomes pessoais. Afirmar que os pronomes substituem os nomes não constitui, de forma alguma, equívoco, porém seria necessário esclarecer como se dá essa substituição e qual a sua natureza.

Distanciando-se da perspectiva adotada pelos gramáticos de Port-Royal, Jakobson (1984) ${ }^{8}$ usou a expressão "shifters" para tratar dos dêiticos pronominais na linguagem. Antes de discutir a natureza dos shifters, Jakobson (1984) fez considerações sobre as funções do código da língua e da mensagem e outros elementos essenciais à comunicação linguística. Segundo o autor, código e mensagem estão sempre em estreita relação um com o outro na comunicação e, por consequência, a mensagem pode se referir ao código ou mesmo à mensagem, e o código igualmente pode se referir à mensagem ou ao próprio código. Para Jakobson (1984), os shifters estariam inseridos justamente na remissão do código à mensagem, pois sua significação não pode ser definida sem que seja considerada a mensagem.

Para falar da natureza funcional dos shifters, Jakobson (1984) recorre a algumas considerações de Peirce (1975) sobre os signos e suas categorias. Partindo de um ponto de vista semiótico, Peirce (1975) assegura que os signos podem ser divididos em símbolos (que seriam aqueles signos que se associam a um objeto por simples convenção social) e índices (que teriam uma relação existencial com o objeto que representam ${ }^{9}$ ); Jakobson (1984, p. 310), então, afirma que os shifters combinariam ao mesmo

\footnotetext{
8 Não tivemos acesso à versão original em inglês desse texto; usamos aqui a versão em espanhol Ensayos de Linguística General que traduziu o termo "shifters" para "conmutadores". Como no português ainda não há uma tradução publicada desse texto, decidimos manter o termo original "shifters".

9 É interessante perceber o caráter relacional dessa abordagem de Peirce (1975), pois, no contexto do pragmatismo, o índice, tal como descrito pelo autor, possui, no instante em que aponta para algo, "uma relação existencial" com o referente que designa. Este, por sua vez, está em constante relação com outros elementos linguísticos e extralinguísticos.
} 
tempo tanto a função de indicar um objeto através de uma convenção social, como possuiriam uma relação existencial com o objeto representado e, por isso, pertenceriam à classe dos símbolos-índice.

Na perspectiva de Jakobson (1984, p. 311) os shifters e, em especial, os pronomes pessoais, têm a propriedade de fazer uma referência particular à mensagem em que estão inseridos, mesmo possuindo um significado geral próprio, isto é, eu significa o destinador da mensagem, enquanto $t u$ representa a condição de destinatário, e assim por diante. Eis uma diferença, segundo Jakobson, entre os shifters e os demais elementos do código linguístico. Jakobson (1984), então, opõe-se à tradicional ideia de que os pronomes pessoais seriam a categoria mais primitiva da linguagem, pois, na verdade, envolvem uma relação complexa na linguagem, na qual o código e a mensagem em questão se entrelaçam. "É por isso que os pronomes são umas das últimas aquisições da linguagem infantil e estão entre as primeiras perdas da afasia" ${ }^{10}$ (JAKOBSON, 1984, p. 311). O autor prossegue tratando da emergência dos pronomes pessoais na fala infantil com a seguinte afirmação:

Se observarmos que inclusive os linguistas podem tropeçar com muitas dificuldades ao tratar de definir o significado geral do termo eu (ou $t u$ ), que significa a mesma função intermitente de sujeitos diferentes, fica muito claro que a criança que aprende a identificarse a si mesma com seu próprio nome não se acostumará facilmente a termos tão alheios como os pronomes pessoais: pode ter de temer falar de si mesma em primeira pessoa quando seus interlocutores lhe chamam $t u$. Às vezes trata de redistribuir estas formas de tratamento. Por exemplo, tratará de monopolizar o pronome de primeira pessoa (...). Ou pode empregar indiscriminadamente $e u$ ou $t u$ tanto para o destinador quanto para o destinatário, de modo que este pronome significará quem quer que participe do diálogo em questão. Ou finalmente a criança substituirá eu por seu nome próprio (...). (JAKOBSON, 1984, p. 311)

Dessa citação, podemos depreender, mesmo que de forma sutil, alguns apontamentos sobre a relação não unívoca entre forma e sentido na linguagem, que encontraremos de forma mais explícita em Benveniste (1989). Como podemos notar, na visão de Jakobson, os pronomes pessoais na linguagem da criança que está adentrado no circuito da língua podem remeter distintamente tanto à primeira pessoa quanto à segunda, a depender da situação em que a criança os emprega. E, em seguida, Jakobson apresenta-nos alguns momentos da passagem do uso do nome próprio (por parte da criança) para fazer referência a si mesma, em dado contexto, ao emprego dos pronomes pessoais.

Chega-se, portanto, na abordagem do autor, à conclusão de que o significado geral dos pronomes teria "a mesma função intermitente dos sujeitos diferentes" (JAKOBSON, 1984, p. 311), o que significa dizer que há uma correlação ao menos implícita entre os pronomes pessoais e uma certa categoria de pessoa.

No rastro das considerações de Jakobson a respeito dos shifters, recorremos a Benveniste para compreender a natureza e a funcionalidade da dêixis pessoal na aquisição da linguagem infantil. Nesse sentido, voltamo-nos para a dêixis pessoal (partículas como "eu", "tu", "meu”, "minha", "teu”, “dele" etc.), pois, como bem afirma Brandão (2001, p.59), a designação dêitica é o primeiro ponto de ancoragem do sujeito na língua e, ao permitir dar um primeiro sentido à noção de subjetividade, constitui a forma inicial de compreensão do processo de subjetivação por que passa o bebê e o centro da problemática da enunciação.

Como dissemos, no curso das diversas perspectivas com que foi abordada, a noção de dêixis sofreu significativas elasticidades e, mesmo aceitando-se as subcategorias criadas talvez com o intuito de delimitar as várias possibilidades de acepção que os dêiticos passaram a designar, havemos de reconhecer que o termo "dêixis" esvaziou-se de sentido, ficando na dependência de um determinante, como "dêixis adverbial ou espacial", "dêixis de pessoa ou pessoal", "dêixis textual ou discursiva",

10 A tradução dessa e de outras citações desta obra para o português é nossa. 
"dêixis de memória", "dêixis verbal", etc. Por essa razão, alguns autores preferiram utilizar outras denominações para se referir a alguns desses fenômenos; é o caso, por exemplo, de Benveniste (1988 e 1989), que se distanciou das abordagens tradicionais da dêixis (inclusive, criticando-as) e preferiu usar o termo "indicadores de subjetividade" para designar partículas que servem à atualização das pessoas no discurso.

Para Benveniste, os indicadores de subjetividade apontam não para uma realidade extralinguística ou para um referente no mundo, mas para o locutor em sua enunciação. Interessa-nos, agora, analisar os postulados teóricos de Benveniste a esse respeito e ver alguns dos desdobramentos que essas questões podem trazer a uma abordagem do sujeito na fase inicial de aquisição da linguagem.

O Dicionário de Linguística da Enunciação (FLORES et al., 2009, p. 140) define o termo "indicadores de subjetividade" como "formas disponíveis na língua utilizadas para convertê-la em discurso, cujo emprego remete à enunciação”. Trata-se, em outras palavras, de formas linguísticas vazias de referência das quais o locutor pode se apropriar para se atualizar no discurso. Esses indicadores remetem, portanto, a uma realidade enunciativa e, por isso, devem ser tomados em relação à instância discursiva em que estão inseridos. É esse caráter sui-referencial dos indicadores de subjetividade que nos leva a perceber que o sujeito está na língua e, por essa razão, deve ser pensado em sua enunciação.

Desse modo, sob a noção de indicadores de subjetividade estão contempladas as categorias que indicam pessoalidade, espacialidade, temporalidade, etc. Todas essas categorias possuem caráter subjetivo, mas é a categoria de pessoalidade que nos interessa aqui. A noção de pessoalidade pode se apresentar de diferentes modos e em diferentes classes de palavras: nas desinências verbais, nos nomes e nos nomes próprios, nos pronomes.

Quanto a esses últimos, Benveniste (1988, p. 288) é categórico: “os pronomes pessoais são o primeiro ponto de apoio para revelação da subjetividade na linguagem”. Os pronomes que remetem à pessoa no discurso são eu/tu, e o ele destina-se à categoria de não pessoa. Benveniste estabelece também uma distinção de caráter subjetivo entre as duas primeiras pessoas: a primeira pessoa possui caráter subjetivo em oposição à segunda.

Com relação à categoria de pessoa $(e u / t u)$, pode-se ainda afirmar sem erro que há nela certa "polaridade", uma vez que ao proferir-se um "eu" nas instâncias enunciativas, instala-se simultaneamente um "tu", a quem o sujeito dirige sua enunciação. Em Benveniste, porém, fica bem marcado que essa polaridade não significa simetria, pois o "eu" vai sempre exercer "uma posição de transcendência" com relação ao "tu", muito embora cada um desses termos não possa ser concebido sem o outro.

Seguindo tal raciocínio, portanto, fica evidente a condição de alocução a que todo processo enunciativo está submetido, pois, segundo Benveniste (1989, p. 84), a mobilização do aparelho formal da enunciação é, para o locutor, a possibilidade de se referir pelo discurso, e, para o alocutário, a possibilidade de correferir do mesmo modo. Assim, fica estabelecido que o processo de referência é parte integrante da enunciação e, partindo dessa premissa, cabe-nos analisar de que modo o sujeito dá a conhecer o processo de constituição subjetiva por que está passando, por meio das marcas linguísticas de sua inscrição no enunciado (dêixis pessoal), quando, valendo-se do aparelho formal da enunciação (BENVENISTE, 1989, p. 81-84), torna próprio o uso da língua e sua reversibilidade em situação de enunciação com o outro.

Mas, se é verdade que o fundamento da subjetividade na linguagem se assenta sobre o uso dos pronomes pessoais, Benveniste questiona a natureza desses pronomes, argumentando que "não remetem nem a um conceito nem a um indivíduo." (1988, p. 288), e prossegue usando como exemplo o "eu", que não se define como uma entidade lexical, mas que refere um ato individual de discurso em que é proferido, designando a presente instância discursiva que o enuncia. Cria-se, assim, uma realidade discursiva na qual o "eu" está inserido, designando o locutor que se enuncia como sujeito. 
Fora dessa realidade, o "eu" adquire um outro sentido. "É, portanto, verdade ao pé da letra que o fundamento da subjetividade está no exercício da língua" (BENVENISTE, 1988, p. 288).

Segundo Benveniste (1988, p. 279), a relação eu / tu ↔ aqui ↔ agora forma a base de constituição do sistema da língua. Dessa base, derivam outras categorias linguísticas como "meu", "teu", "hoje", "amanhã", "neste lugar" etc. Para ele, os dêiticos contêm o indicador de pessoa, sendo que dessa referência emerge seu caráter cada vez único e particular no ato de enunciação. Nesse sentido, Flores et al. (2008) afirmam:

Enfim, mesmo que o assunto exija maiores explicações, é possível dizer sem incorrer em equívoco, que Benveniste, ao propor a noção de aparelho formal da enunciação, considera que a língua, como sistema que é, tem em sua organização (estrutura) um aparelho formal que possibilita ao sujeito enunciar nesta língua. O aparelho (indicadores de subjetividade, tempos, modos etc.) como tal pertence à língua, mas seu uso é dependente da enunciação. Ou seja, o conceito de enunciação está ligado ao princípio da generalidade do específico. (FLORES et.al., 2008, p.22).

Desse modo, podemos pensar que a visão de língua de Benveniste comporta elementos formais para expressão da subjetividade (os indicadores de subjetividade, entre outros) que estão em um plano mais geral ou mesmo universal, e esses indicadores permitem ao sujeito revelar a singularidade de sua existência na / pela linguagem. Em outras palavras, poderíamos dizer que, em Benveniste, o aparelho formal da enunciação é, a um só tempo, universal e particular. Analisando a questão, Flores et al. (2008) prosseguem nos dando a seguinte formulação: “é universal que todas as línguas tenham dispositivos que permitam sua utilização singular pelos sujeitos; é particular a configuração destes sistemas e o uso que os sujeitos fazem deles.” (FLORES et.al., 2008, p.22, destaques dos autores).

\section{Observações metodológicas para análise dos dados}

A metodologia a ser utilizada para investigação e análise do objeto revela muito da postura teórica assumida pelo investigador de qualquer campo teórico; a escolha do próprio objeto é determinada pelo viés da teoria com a qual o pesquisador decide trabalhar. "O ponto de vista cria o objeto", afirmou Saussure (2006).

Por outro lado, o objeto de estudo também apresenta suas demandas para a leitura que o investigador irá fazer e para a teoria que subsidiará a pesquisa. É, de fato, uma via de mão dupla. Em nosso caso, não é diferente. O trabalho na interface entre a Aquisição da Linguagem e a Linguística da Enunciação apresenta algumas questões e outros impasses às análises dos dados.

Aliás, o próprio dado enunciativo na aquisição da linguagem constitui um dilema: para Flores (2008), por exemplo, quando tratamos de enunciação, "o dado não é jamais 'dado", pois a forma com que se chega aos dados traz consigo aspectos da observação e da descrição do observador. Assim, compete-nos proceder a alguns esclarecimentos a respeito dos procedimentos metodológicos adotados para realização do presente trabalho.

Nossa pesquisa se pauta na observação da relação mãe-bebê em situações naturalísticas de interação, melhor dizendo, partimos das produções enunciativas da mãe e do bebê em contextos naturalísticos para investigar nosso objeto. A esse respeito, convém lembrar uma observação feita por Silva (2009):

(...) numa situação de coleta de dados, por mais que se busque a neutralidade, o fato de a fala ser objeto de estudo envolve o que Labov (1971) chama de "o paradoxo do observador". Nesse caso, um desconhecido - o pesquisador - ao procurar amostras de linguagem por meio de entrevistas controladas, pode afetar a desenvoltura da criança ao falar, por perceber esse contexto como diferente daquele natural em que interage. (SILVA, 2009, p.191). 
O corpus de que dispomos é constituído essencialmente por dados orais e se integra aos corpora gerais do projeto "A gênese da referência" (GERE) ${ }^{11}$. Trabalhamos aqui, especificamente, com as díades $\mathrm{B}$, e $\mathrm{C}$ que, em termos quantitativos, somam 57 sessões já transcritas, que compreendem a faixa etária de 00 a 36 meses de vida da criança.

Interessa-nos principalmente (embora não apenas) as produções da criança no período que compreende 12 e 32 meses, por razões impostas pela natureza de nossa pesquisa: nos fragmentos observados, os dêiticos de pessoa não aparecem nas produções enunciativas do bebê no período anterior a esse. Neste artigo, iremos apresentar e analisar dados de produções enunciativas do bebê na faixa etária entre 04 e 31 meses.

Os dados a serem analisados correspondem a registros quinzenais feitos em videocassete e em DVD, com duração média de vinte minutos cada, gravados em situação natural na casa dos participantes das díades. Optamos por fazer um estudo longitudinal, de caráter qualitativo e interpretativo, sobre a emergência, o funcionamento e o papel dos dêiticos pessoais na fala da criança.

A transcrição dos dados das produções enunciativas na aquisição da linguagem infantil, como qualquer outro tipo de transcrição, está inevitavelmente sujeita a interpretações do investigador, e a aparente imparcialidade dos dados não passa de uma ilusão. Isso porque, como todo ato de enunciação, a transcrição carrega consigo elementos da subjetividade do enunciador, porém ela apresenta uma particularidade: é um ato de enunciação que tenta representar outro ato de enunciação. Esse caráter metalinguístico traz à transcrição outra questão imposta pela natureza efêmera da enunciação, que se apresenta como única e irrepetível; ou seja, o dado da enunciação não pode traduzir nem os reais interesses dos sujeitos envolvidos na cena enunciativa nem as circunstâncias (de tempo, de situação, de lugar, etc.) em que é produzido. Isso nos impele a concordar com Flores et al. (2008, p. 42) quando afirmam que "a situação do discurso a ser transcrita tem seu estatuto alterado". Os autores prosseguem apresentando uma distinção entre o "dado enunciativo" e o "fato enunciativo"; este último, na visão dos autores, é entendido como um fenômeno que serve para explicitar "a maneira pela qual o sujeito se marca naquilo que diz". Desse modo, a noção de "fato enunciativo", posta dessa maneira, parecenos mais conveniente, sobretudo porque assume de forma explícita ser produto de uma interpretação. Em nosso caso, para proceder à análise, segmentamos os fatos enunciativos entre mãe-bebê e os apresentamos em fragmentos.

Por fim, cabe trazer algumas observações feitas pelo autor no tangente ao assunto:

a) transcrever é a condição da análise empreendida, sendo até mesmo uma etapa da análise, podendo ser estendida a estudos de diferentes corpora, inclusive de natureza gráfica;

b) cada transcrição é sempre única, singular e não linearmente extensível;

c) a transcrição não pode ser considerada integral, nem mesmo pode ser generalizável. (FLORES et al., 2008, p. 42).

Os dados que selecionamos foram expostos aqui em fragmentos e fizemos uma transcrição ortográfica da fala, colocando entre parênteses algumas informações que julgamos importantes à compreensão da cena enunciativa. Para representar a fala da mãe, utilizamos a letra M, e, para indicar a fala da criança, usamos a letra C no início da transcrição.

11 O projeto GERE foi desenvolvido, em parte, por nós, no Laboratório de Aquisição de Fala e Escrita (LAFE) da Universidade Federal da Paraíba, sob a orientação da Prof. ${ }^{a}$ Dr. ${ }^{a}$ Marianne C. B. Cavalcante. Em síntese, o projeto GERE se voltou para análise de fatos enunciativos na fala infantil sob o escopo de compreender o processo de constituição da referência (pessoal e espacial) na aquisição da linguagem. Para isso, as pesquisas nele desenvolvidas se detiveram em análise de dados presentes em gravações feitas em vídeos e em DVD de situações de interação entre mães e seus bebês em casa. 


\section{Análise dos dados}

A partir do nascimento, a criança é inserida em uma estrutura dialógica por meio de uma fala atribuída materna em que a mãe fala "como se" fosse o bebê, dando-lhe significação, atribuindolhe "voz", configurando, assim, uma instância inicial de funcionamento da língua (CAVALCANTE, 1999). O lugar de terceira pessoa no discurso atribuído materno para se referir tanto à criança quanto à mãe é bastante frequente, como vemos nos exemplos a seguir:

Fragmento 1: DIADE B, IDADE: $04 \mathrm{~m} 15 \mathrm{~d}$

M "Olha o pintinho mãezinha!"

M “Bora brincar mamãe?"

M “Cadê Vitor hein, mamãe?"

Fragmento 2: DÍADE B, IDADE: $09 \mathrm{~m} 12 \mathrm{~d}$

M “Oxe, mãe!"

Fragmento 3: DÍADE C, IDADE: $31 \mathrm{~m} 21 \mathrm{~d}$

M “Achô mãe!"

É perceptível, pois, nestes diferentes momentos de interação que a posição de terceira pessoa referindo-se ao bebê no discurso materno, ao longo dos primeiros 36 meses, é muito comum, mas logo a criança começa a fazer uso de pronomes pessoais para marcar seu lugar e o da mãe no discurso e a posicionar-se como sujeito de seu próprio discurso, quando então o uso do pronome pessoal eu se torna mais frequente (CAVALCANTE, 2006).

A compreensão desse processo gradual de subjetivação que se efetiva nos deslocamentos subjetivos, marcados a princípio na fala materna e depois na fala do infans, implica algumas considerações acerca da linguagem, pois é nela que se explicita a singularidade da relação mãe-bebê como espaço de constituição do sujeito. Assim, nos voltamos não para os enunciados, mas para o processo de enunciação, pois é nele que observamos as mudanças de relação do sujeito com a língua e é também o lugar em que o sujeito se instaura.

Sendo assim, o uso da dêixis pessoal evidencia o processo de construção subjetiva dos parceiros (o bebê em especial) e, como já mostramos, os dêiticos são usados tendo por base o ponto de vista da mãe, ou seja, para desenvolver a atividade referencial, a criança precisa deslocar-se de seu ponto de vista e levar em consideração o ângulo de visão da mãe, considerando o lugar que o outro materno está ocupando.

Tal deslocamento é imprescindível à constituição do sujeito, pois permite ao infans não apenas desenvolver referência com relação ao ambiente e à situação interativa, mas também e principalmente construir o seu ponto de vista levando em conta o olhar do outro, posicionar-se em relação a ele, lidando, deste modo, com a intersubjetividade, que é condição à comunicação linguística e às interações discursivas.

Assim, o eu e o outro se imbricam e se implicam no processo de constituição de subjetividade, em uma relação dialética e necessária à aquisição da linguagem e, nas palavras de Benveniste (1988, p. 286), "é na e pela linguagem que o indivíduo se constitui como sujeito”. A linguagem é, portanto, a condição necessária à subjetividade.

Partindo dessas considerações e tomando agora como pressupostos o fato de que os termos 'sujeito' e 'eu' não são termos que necessariamente se recobrem e de que o uso do pronome 'eu' na infância nem sempre possui uma implicação de subjetividade, como já discutimos, mas por vezes explicita a instabilidade presente no processo gradual de constituição do sujeito, buscaremos mostrar de que modo a alternância dos dêiticos pessoais nos discursos da mãe e da criança é reveladora dos 
deslocamentos e da constituição subjetivos.

Para Benveniste (1988), os pronomes pessoais são os primeiros pontos de apoio para expressão de subjetividade. Pode-se afirmar, desse modo, que o uso da dêixis pessoal na relação mãe-bebê evidencia o processo de subjetivação por que passa a criança que, nos primeiros meses, ainda depende da fala atribuída materna, mas logo irá assumir sua posição de sujeito de seu discurso.

Assim, verificamos o uso alternado de pronomes pessoais em diferentes díades mãe-bebê, sobretudo o eu e o tu, como também os dêiticos que a eles se referem (como meu, minha, teu, tua, dele, dela etc.) marcados, a princípio, na fala da mãe e, depois, na fala do bebê, e que refletem de certo modo as oscilações e os deslocamentos subjetivos presentes nas interações estabelecidas entre os parceiros da díade.

No período inicial da relação mãe-bebê, verifica-se tanto a ocorrência do uso de dêiticos pessoais verbais, quanto a de dêiticos pessoais gestuais, ou seja, o uso indicativo do apontar referindo-se aos participantes do discurso. Com relação aos primeiros, o uso de dêiticos pessoais verbais é bastante frequente na fala da mãe ao passo que verifica seu uso progressivo nas produções da criança. Porém, na fala da mãe, os pronomes pessoais alternam-se, ocorrendo também com frequência gradativa, pois, nos meses iniciais, a mãe ora usa os termos ' mãe', 'mãezinha' e suas variantes para se referir a ela mesma, ora usa o eu, indicativo de pessoa. O mesmo fato pode ser verificado quando a mãe faz referência ao bebê, como podemos observar no exemplo a seguir:

Fragmento 4: DÍADE C, IDADE: 3 meses e 12 dias

A mãe está trocando as roupas do bebê

$\mathrm{M}$ - Cadê Vitória? Cadê a nenê de mamãe? Cadê ela?

C - (Mexe os braços e olha para mãe)

M - Achô mamãe. Achô. (...)

$\mathrm{M}$ - Eu tô aqui mamãe, eu tô aqui (em falsetto)

Neste fragmento, verificamos o uso dos termos 'Vitória', 'nenê da mamãe' e 'ela' para fazer referência ao bebê, o que de certo modo revela a posição de objeto no discurso da mãe que a criança ocupa. O pronome eu também aparece no diálogo, sem haver, entretanto, uma clara alusão ao sujeito / locutor do discurso, pois o eu aí é usado em uma fala que a mãe atribui ao bebê como se ela fosse objeto de seu discurso.

São comuns na fala da mãe as oscilações do lugar discursivo ocupado pelo infans, visto que ele ora é objeto ('o nenê de mamãe'), ora ele é o sujeito de uma fala atribuída ('eu tô aqui mamãe'). Estas oscilações também são observadas nos meses mais avançados, mas aos poucos os lugares dos parceiros dialógicos começam a ser delineados (CAVALCANTE, 2006).

Fragmento 5: DÍADE B, IDADE: 18 meses e 10 dias

A mãe e o bebê estão brincando com a bola na sala.

$\mathrm{M}$ - Olhi u qui tia Marianni faz, cunversi cum ela, si você num

queria sê filmadu cunversi cum tia

Mari, ó Ninhu, olha pra ela vai Ninhu, ficô tímidu foi?Foi?

C - (bebê está de pé alternando o olhar entre a mãe e a câmera).

$\mathrm{M}$ - mãe

C - (aponta)

M - É Mari? 
$\mathrm{C}-\dot{\mathrm{E}}(\ldots)$

M - (...) Cadê, cheuvê, deixa eu vê si tá gostosu, tá gostosa

M - (...) Então desça pra buscá. Assim você cai viu?

Boti a bola pra cá, venha pra cá, venha

C - a bola

Nesta situação, a mãe interage com o bebê marcando claramente sua posição enquanto enunciadora de seu discurso através do eu e para se referir a ele usa o pronome você, distintamente da situação analisada anteriormente. Agora, a criança não mais depende da fala atribuída materna e já é capaz de posicionar-se (instaurar-se) como sujeito de seus enunciados.

Aos poucos a criança que se encontrava em uma posição de objeto da fala materna, começa a se colocar como um sujeito-falante. E é neste momento que o uso do pronome 'eu' no discurso materno começa a se tornar mais presente, e o bebê passa a ser tomado como um interlocutor na dialogia (CAVALCANTE e NASLAVSKY, 2006), e, de um processo especular ao discurso da mãe, surge um interactante capaz, agora, de posicionar-se como sujeito no discurso e isso fica explicitado no uso da dêixis pessoal.

\section{Considerações Finais}

Do que foi exposto até agora, torna-se evidente que a dêixis funciona como forte ponto de sustentação para inserção do infans no sistema da língua, revelando ainda as mudanças de posicionamento da criança com relação à linguagem e à sua subjetividade, bem como o processo de constituição subjetiva pelo qual passa em aquisição de linguagem. Coube-nos, então, nesta pesquisa, analisar de que modo o processo de constituição subjetiva, tal como postulado por Benveniste, pode ser revelado no aparecimento e no uso da dêixis pessoal na fala do bebê em situação de interação com a mãe. E priorizamos uma visão enunciativa porque, por razões que acreditamos já estarem explícitas, pensamos que a relação entre constituição subjetiva e aquisição de linguagem precisa ser tomada sob uma ótica enunciativa. E para isso deixamos clara nossa filiação teórica a Benveniste, pois nele podemos encontrar a tese, cremos que agora mais clara, de que é o movimento de enunciação que recria indefinidamente o sujeito (BENVENISTE, 1988, p. 285), que para se instaurar precisa de um lugar para si no discurso - a dêixis pessoal.

Após a análise e discussão que levantamos aqui, vemos que a categoria de pessoa é o fundamento linguístico da intersubjetividade, e a sua referência diz respeito, sobretudo, ao eu / tu e aos demais dêiticos que a eles se referem. Nesse sentido, concordamos com Flores e Teixeira (2001, p. 42) quando afirmam que "o mecanismo da dêixis está marcado na língua e é colocado em funcionamento cada vez que o sujeito enuncia". Em aquisição, a emergência dos dêiticos na fala do bebê revela as mudanças de sua relação com a língua e o processo de constituição subjetiva por que está passando.

Assim, muito embora possuam um lugar na língua, os dêiticos são categorias vazias de referencialidade e, ao mesmo tempo, possuem caráter subjetivo, porque revelam a instauração do sujeito, quando, valendo-se da dêixis pessoal, torna singular sua inscrição no uso da língua.

É necessário enfatizar, nestas últimas considerações, a relação intrínseca existente entre a aquisição de linguagem e o processo de constituição do sujeito, revelada no ato mesmo de conversão da língua em discurso, sobretudo, na emergência da dêixis pessoal, como marca da inscrição do sujeito em sua enunciação. 


\section{Referências}

ARnAUld, A. e LANCElot, C. Gramática de Port-Royal. Tradução de BASSETTO, B. e MURACHCO, H. São Paulo: Martins Fontes, 1960/1992.

APOTHÉlOZ, D. Papel e funcionamento da anáfora na dinâmica textual. In: CAVALCANTE, M. M., RODIGUES, B. B. e CIULLA, A. (Orgs.) Referenciação. São Paulo: Contexto, 2003, p. 53-84.

BENVENISTE, E. Problemas de Linguística Geral I. 2. ed. Campinas, SP: Pontes: Editora da Universidade Estadual de Campinas, 1988.

BENVENISTE, E. Problemas de Linguística Geral II. 2. ed. Campinas, SP: Pontes: Editora da Universidade Estadual de Campinas, 1989.

BRANDÃO, Helena H. Nagamine. Da língua ao discurso, do homogêneo ao heterogêneo. In: BRAIT, Beth. (Org.). Estudos enunciativos no Brasil: histórias e perspectivas. Campinas, SP: Pontes: São Paulo: Fapesp, 2001, p. 59-69.

BRÉAL, Michel. Essai de Sémantique: science des significations. França: Hachette, 1924 [1897].

CAVALCANTE, M Marianne C. B. Da voz à língua: a prosódia materna e o deslocamento do sujeito na fala dirigida ao bebê. Tese de Doutoramento. IEL/UNICAMP, 1999.

CAVALCANTE, M Marianne C. B. Aquisição da linguagem: nas trilhas do interacionismo. Cadernos do LAFE, v. 1, p. 12-17, 2006.

CAVALCANTE, Marianne C. B. e NASLAVSKY, J. P. N. O lugar de sujeito nas interações mãe-bebê. Revista do GELNE (UFC), v. 6, p. 57-67, 2006.

FLORES, Valdir do Nascimento. Princípios para definição do objeto da linguística da enunciação. In: BARBISAN, Leci e FLORES, V. (Org.). Estudos sobre enunciação, texto e discurso. Revista Letras Hoje. Porto Alegre: EDIPURS, p. 97-126, 2001.

FLORES, Valdir do Nascimento; TEIXEIRA, Marlene. Introdução à Linguística da Enunciação. São Paulo: Contexto, 2005.

FLORES, V. do Nascimento et al. Enunciação e gramática. São Paulo: Contexto, 2008.

FLORES, V. do Nascimento et al. Dicionário de Linguística da Enunciação. São Paulo: Contexto, 2009.

HANKS, William F. Língua como prática social: das relações entre língua, cultura e sociedade a partir de Bourdieu e Bakhtin. In: BENTES, A. Cristina; REZENDE, Renato e MACHADO, M. Antônio (Org.). São Paulo: Cortez, 2008.

HUMBOLDT, Alexander. Cosmos: ensayo de una descripcion física del mundo. Trad. Bernardo Giner e Jose de Fuentes. Madrid: Gaspar e Roig Editores, Tomo I, II, III e IV, 1874.

JAKOBSON, R. Ensayos de Linguística Geral. Barcelona: Editorial Ariel, 1984.

JESPERSEN, Otto. The Philosophy of Grammar. London: Allen e Unwin, 1923.

LAHUD, M. A Propósito da Noção de Dêixis. São Paulo: Ática, 1979.

LEVINSON, Stephen C. Pragmática. Trad. de BORGES, L. e MARI, A. São Paulo: Martins Fontes, 2007.

LYONS, J. Semantics 1. Cambridge: University Press, 1977.

MARCUSCHI, L. A. A dêixis discursiva como estratégia de monitoração cognitiva. In: KOCH, I. G. V. e BARROS, K. S. M. Tópicos em Linguística de texto e análise da conversação. Natal: EDUFRN, 1997, p. 156-171.

PEIRCE, C. S. Semiótica. São Paulo: Perspectiva, 1975. 
POSSENTI, Sírio. O que significa “o sentido depende da enunciação”?. In: BRAIT, B. (Org.) Estudos enunciativos no Brasil: histórias e perspectivas. São Paulo: Pontes, 2001, p. 187-199.

SILVA, Carmem L. da Costa. A criança na Linguagem: enunciação e aquisição. Campinas, SP: Pontes Editores, 2009.

TEIXEIRA, Marlene. Análise de Discurso e Psicanálise: elementos para uma abordagem do sentido no discurso. Porto Alegre: EDIPUCRS, 2000. 
